\title{
Evaluation of cognitive impairment in patients with episodic migraine
}

\author{
Avaliação do comprometimento cognitivo em pacientes com migrânea episódica
}

Caroliny Trevisan Teixeira ${ }^{1}$, Carolina Minarro Cremasco¹, Anelise Melo', Carolina Cáfaro', Marcelo Cedrinho Ciciarelli', Karen dos Santos Ferreira ${ }^{1}$

DOI 10.5935/2595-0118.20180039

\section{ABSTRACT}

BACKGROUND AND OBJECTIVES: The purpose of this study was to evaluate the presence of cognitive deficits in patients with episodic migraine and control group, and to compare with the results previously described in the literature.

METHODS: Patients with episodic migraine were included according to the International Headache Society criteria, and a control group was selected, matched by sex, age, and schooling. Patients were asked about the frequency and intensity of headaches, medications used, and comorbidities. Afterwards, a neuropsychological assessment was applied using the Montreal Cognitive Assessment, the clock drawing test, the verbal fluency test, and the Stroop test. The main variables influencing cognitive dysfunctions were analyzed (depressive disorder, anxiety disorder, sleep disorder, use of medication).

RESULTS: Thirty patients with episodic migraine and 30 controls were evaluated. Patients with episodic migraine had a performance in the Montreal Cognitive Assessment test $(\mathrm{p}=0.53)$, the clock drawing test $(\mathrm{p}=0.80)$, the verbal fluency test $(\mathrm{p}=0.44)$ and the Stroop test $(\mathrm{p}=0.97)$ similar to the control group. Patients with chronic migraine (30 patients and 30 controls) performed a Montreal Cognitive Assessment test $(\mathrm{p}=0.00)$, verbal fluency test $(\mathrm{p}=0.00)$ and Stroop test $(\mathrm{p}=0.00)$ lower than the group control. The main variables influencing cognitive disorders were studied by linear regression, and none of these variables was an influencing factor in the Montreal Cognitive Assessment test.

CONCLUSION: Patients with episodic migraine did not present cognitive deficits compared to a control group.

Keywords: Cognitive dysfunctions, Headache, Migraine.

1. Centro Universitário Barão de Mauá, Faculdade de Medicina, Ribeirão Preto, SP, Brasil.

Submitted in January 31, 2018.

Accepted for publication on June 11, 2018.

Conflict of interests: none - Sponsoring sources: none.

Correspondence to:

Rua Ramos de Azevedo, 429 - Jardim Paulista

14090-180 Ribeirăo Preto, SP, Brasil.

E-mail: carol._teixeira@hotmail.com

(c) Sociedade Brasileira para o Estudo da Dor

\section{RESUMO}

JUSTIFICATIVA E OBJETIVOS: A proposta deste estudo foi avaliar a presença de déficits cognitivos em pacientes com migrânea episódica e grupo controle, e comparar com os resultados previamente descritos na literatura.

MÉTODOS: Foram incluídos pacientes com migrânea episódica, segundo os critérios da International Headache Society, e selecionado um grupo controle pareado por sexo, idade e escolaridade. Os pacientes foram questionados sobre a frequência e intensidade de crises, fármacos, comorbidades. Posteriormente, foi realizada a avaliação neuropsicológica através do Montreal Cognitive Assessment, do teste do relógio, teste da fluência verbal e Stroop teste. As principais variáveis influenciadoras de distúrbios cognitivos foram analisadas (transtorno depressivo, transtorno de ansiedade, distúrbios do sono, uso de fármacos).

RESULTADOS: Foram avaliados 30 pacientes com migrânea episódica e 30 controles. Os pacientes com migrânea episódica apresentaram uma performance no Montreal Cognitive Assessment teste $(\mathrm{p}=0,53)$, teste do relógio $(\mathrm{p}=0,80)$, teste da fluência verbal $(\mathrm{p}=0,44)$ e Stroop teste $(\mathrm{p}=0,97)$ semelhante ao grupo controle. Pacientes com enxaqueca crônica (30 pacientes e 30 controles) realizaram um teste de Montreal Cognitive Assessment teste $(\mathrm{p}=0,00)$, teste de fluência verbal $(\mathrm{p}=0,00)$ e teste de Stroop $(\mathrm{p}=0,00)$ menor que o grupo controle. As principais variáveis influenciadoras de distúrbios cognitivos foram estudadas através de regressão linear e nenhuma dessas variáveis apresentou-se como fator de influência no Montreal Cognitive Assessment.

CONCLUSÁO: Os pacientes com migrânea episódica não apresentaram déficits cognitivos em comparação com um grupo controle. Descritores: Cefaleia, Disfunção cognitiva, Migrânea.

\section{INTRODUCTION}

In general, headache is a frequent symptom in the population, with a lifetime prevalence of $93 \%$ in men and $99 \%$ in women. Headache is the main reason for neurological consultations in outpatient care. It is estimated that 5 to $10 \%$ of the population seek medical attention during their lifetime due to headache ${ }^{1,2}$. The main primary headaches are of the tensional type and the migraine. Migraine is a type of cranial pain lasting from 4 to 72 hours, characterized by strong intensity, throbbing or pulsatile, worsening with daily activities, being unilateral in $2 / 3$ of the cases, and may be accompanied by symptoms such as nausea, vomiting, photophobia, and phonophobia. There may be five detectable phases in a typical migraine attack: prodrome or premonitory symptoms, aura, headache, associated symptoms (nausea, photophobia) and postdrome (fatigue, exhaustion) $)^{3-5}$. 
Patients with chronic pain often report cognitive complaints that impair their social situations and activities of daily living. According to a meta-analysis published in 2013, the authors concluded that there is a greater change in cognitive tests of patients with chronic pain when compared to normal volunteers, despite the significant heterogeneity of the studies included in the analysis $^{6}$. It was also suggested that future research is done as well as standardized testing methods.

Several studies have analyzed the association between migraine and cognitive function, but the results of these studies are diverse. Some cross-sectional studies found no difference between patients with migraine and controls ${ }^{7-11}$, while others demonstrated evidence of worse cognitive performance among migraine patients ${ }^{12-15}$. Several tests were used to assess cognitive function, and many of these studies were small, which may limit their ability to detect differences between groups.

Conventional magnetic nuclear resonance (MNR) studies have discovered that patients with migraine have an increased risk of ischemic lesions in the white matter, sometimes referred to as the "substrate for migraine". This risk exists for patients with and without aura, and it is being increased in patients with migraine with aura and chronic migraine. Cumulative migraine effects on the central nervous system (CNS) have been demonstrated, although the functional implication of these results remains unclear. In the long term, it is believed that these lesions would cause cognitive deficits in these patients ${ }^{16}$.

There are important confusing factors when evaluating a patient with migraine and cognitive complaints. First of all, many of these patients present depressive disorder or anxiety disorder, comorbidities that are related to attention deficit and impaired performance in cognitive tests. Secondly, some drugs commonly used by patients with migraine, such as topiramate, have been reported to cause cognitive deficits ${ }^{17,18}$. A study published in 2013, evaluating 30 patients with chronic migraine and 30 healthy controls, detected a low performance in cognitive tests in patients with chronic migraine, apparently unrelated to other factors ${ }^{12}$.

The results of functional MNR in patients using topiramate and controls found deficits in the language network areas. These data suggest a mechanism by which this drug impairs cognitive processing during language function, both for chronic and single dose $\mathrm{e}^{18}$. Another double-blind controlled study, published in 2011, found that topiramate causes dose-dependent cognitive deficits after six weeks of use ${ }^{19}$.

Thus, this study aimed to evaluate the presence of cognitive deficits in patients with a episodic migraine and to compare them with the results previously described in the literature. Also, it aimed at evaluating the main triggers of cognitive disorders present in the migraine population, such as depressive disorder, anxiety disorder, use of CNS medications such as topiramate, non-restorative sleep, alcohol abuse, history of trauma cranial and other comorbidities.

\section{METHODS}

A cross-sectional descriptive study was carried out at Centro Universitário Barão de Mauá School of Medicine, with students from this course. Students over 18 years old of both genders, with a episodic migraine with or without aura (transient neurological disorders accompanying headache) were included. The International Headache Society (IHS) criteria were followed: pain lasting 4 to 72 hours, characterized by strong intensity, throbbing or pulsatile, worsening with daily activities, and may be accompanied by symptoms such as nausea, vomiting, photophobia and phonophobia, occurring for less than 15 days in the month. The exclusion criteria were patients with brain dysfunction that prevented from responding to questionnaires, patients who did not agree to sign the Free and Informed Consent Form (FICT).

Students were interviewed personally for the evaluation of demographic data and clinical data, as well as neuropsychological tests for cognitive assessment. A control group (CG) was formed, matching patients by gender, age and schooling, without a diagnosis of migraine.

Considering that the previous study found significant differences in cognitive tests by the Montreal Cognitive Assessment (MoCa) applied in women with chronic migraine and controls (groups of 30 cases and 30 controls) (Table 1). A sample calculation was performed considering the difference between the MoCa test results among the two groups and the standard deviation of the results (Table 2). For a test strength of $90 \%$ accuracy, it was estimated that the "migraine" and "control" groups should have at least 27 members each. Comparison between the groups was based on the Student $t$-test, and the equation for the sample calculation was ${ }_{\mathrm{n}} \frac{2 \sigma^{2}\left(Z_{\alpha / 2}+Z_{\beta}\right)^{2}}{\left(\mu_{1}-\mu_{2}\right)^{2}}$, where $\mu_{1}$ and $\mu_{2}$ are the means of the $\mathrm{MoCa}$ score in the groups with and without migraine, respectively, and $\sigma$ is the population's standard deviation obtained from the study by Ferreira et al. ${ }^{20}$

Table 1. Descriptive of the Montreal Cognitive Assessment score in each group ${ }^{20}$

\begin{tabular}{lccc}
\hline Migraine & $\mathrm{n}$ & Mean & Standard deviation \\
\hline With & 30 & 24.4 & 2.6 \\
Without & 30 & 26.7 & 1.8 \\
\hline
\end{tabular}

All sample sizes presented here were calculated considering a bilateral hypothesis test, the highest standard deviation (2.6), with a significance level of $5 \%$ and with variations in test strength of 70 to $90 \%$ and a minimum difference of 2.3 (found in the study).

Table 2. Sample sizes considering the comparison of the two groups

\begin{tabular}{lcc}
\hline Difference between means & Test strength (\%) & $\mathrm{n}$ (per group) \\
\hline 2.3 & 70 & 16 \\
& 75 & 18 \\
& 80 & 21 \\
& 90 & 27
\end{tabular}

Note: The calculated sample sizes refer to the total number of patients that should be collected in each of the two groups (with and without pain).

\section{CLINICAL DATA}

Data such as age, gender, headache diagnosis, frequency and severity of headache attacks, doses of drugs used, and analgesic use 
were evaluated through interviews. Patients were also assessed for comorbidities such as depressive disorder and anxiety disorder (Diagnostic and Statistical Manual of Mental Disorders - DSM$5)^{21}$, sleep aspects ("Do you have any type of sleep problem such as insomnia, non-restorative sleep or sleep apnea?"), drug use ("Do you use any type of drug that require continuous use?"), and other comorbidities that have been previously diagnosed by other physicians, such as hypothyroidism, diabetes and hypertension, as well as questions about impact on the quality of life of these patients.

Subsequently, the patients were submitted to a neuropsychological evaluation that included the validated MoCa test for Portuguese $^{22}$, verbal fluency, Stroop test (for attention and working memory) $)^{23}$.

This study was approved by the Ethics Committee of the Centro Universitário Barão de Mauá, CAAE 38707014.3.0000.5378 (2015).

\section{Statistical analysis}

The data were analyzed by the SPSS program version $18.0^{24}$. In the categorical variables analysis, the Chi-square or Fisher's Exact test was applied, according to the expected frequency in the cells. In the numerical variables analysis, Kolmogorov-Smirnov tests were applied to define the type of variables distribution; for those that had a normal distribution, parametric tests such as the Student $t$ test or the Variance Analysis (ANOVA) were used. The variables that did not present normal distribution were evaluated with the non-parametric Mann-Whitney test. In order to correlate two or more variables, binary logistic regression analysis, and linear regression were used.

\section{RESULTS}

A total of 64 students were approached. Three controls were excluded because they presented intense and frequent tensional headache. One student was excluded because he had no migraine attacks for more than one year. Finally, 60 students were included in the study, 30 of them with a episodic migraine and 30 controls. The demographic data of the episodic migraine group (EMG) and control group (CG) are described in table 3.

Table 3. Demographic data of patients in both groups

\begin{tabular}{lcc}
\hline & $\mathrm{EMG} / \mathrm{n}=30$ & $\mathrm{CG} / \mathrm{n}=30$ \\
\hline Mean age (years) & 23.5 & 22.3 \\
Female & $29(96.7 \%)$ & $29(96.7 \%)$ \\
Civil status single & $28(93.3 \%)$ & $30(100 \%)$ \\
\hline
\end{tabular}

$\mathrm{EMG}=$ episodic migraine group; $\mathrm{CG}=$ control group.

Regarding the characteristics of migraine and the impact on daily and work activities, the results are described in table 4.

Among the drugs used by EMG, 18 (60\%) patients used contraceptives, $2(6.7 \%)$ used topiramate, $2(6.7 \%)$ use antidepressants, 3 (10\%) used beta blockers, 1 (3.3\%) used flunarizine, and $1(3.3 \%)$ used chlorpromazine. The most commonly used analgesics were dipyrone (15-50\%), ergotamine (2-6.7\%) and non-hormonal anti-inflammatory (5-16.7\%). The frequency of
Table 4. Characteristics of headache in the episodic episodic migraine group

\begin{tabular}{lc}
\hline Characteristics & EMG (n and \%) \\
\hline Pulsatile & $25(83.3)$ \\
Nausea & $24(80)$ \\
Photophobia & $27(90)$ \\
Phonophobia & $22(73.3)$ \\
Aura & $17(56.7)$ \\
Use of topiramate & $2(6.7)$ \\
Harms the activities & $27(90)$ \\
Absenteeism at work & $17(56.7)$ \\
Visual pain scale (mean \pm SD) & $8.5 \pm 1.1$ \\
Pain time (years) (mean \pm SD) & $7.0 \pm 4.4$ \\
Frequency (days/month) $($ mean $\pm S D)$ & $4.5 \pm 3.4$ \\
\hline
\end{tabular}

analgesic use was $4.4 \pm 4.2$ days/month. Only 2 (11.1\%) were abusers of ergotamine.

Among the CG patients, the most used drugs were contraceptives (18-60\%), antidepressants (1-3.3\%).

The most common comorbidities in EMG were generalized anxiety disorder (10-33.3\%), major depressive disorder (2-6.7\%), hypothyroidism (3-10\%), non-restorative sleep (12-40\%) and hypertension (1-3.3\%). There were no patients with diabetes or previous head trauma. The use of caffeine was present in $12-40 \%$ and the use of alcohol in $9-27 \%$.

The most common comorbidities in the CG were generalized anxiety disorder (6-20\%), non-restorative sleep (5-16.7\%), hypothyroidism (2-6.7\%). No patient reported major depressive disorder, hypertension, diabetes, previous head trauma. The use of caffeine was present in 10-30\% and the use of alcohol in 16$53.3 \%$.

Among the patients interviewed, 2 (6.7\%) had complaints of memory impairment in the EMG and $2(6.7 \%)$ in the CG. Regarding the applied cognitive tests, the main results are described in table 5. When applied the linear regression, using $\mathrm{MoCa}$ as a dependent variable and episodic migraine, anxiety disorder, depressive disorder, use of topiramate and non-restorative sleep as independent variables, none of these variables was an influencing factor in MoCa (Table 6).

Table 5. Patients with a episodic migraine and controls: mean scores on neuropsychological tests

\begin{tabular}{lccc}
\hline Tests & EMG & CG & p-value* \\
& $\mathrm{n}=30$ & $\mathrm{n}=30$ & \\
\hline MoCa & 27.4 & 28.0 & 0.53 \\
Verbal fluency & 13.6 & 14.4 & 0.44 \\
(n words) & & & \\
Clock test & 2.7 & 2.7 & 0.80 \\
Stroop (1) & 15.1 & 15.1 & 0.97 \\
Stroop (2) & 15.7 & 16.2 & 0.48 \\
Stroop (3) & 22.6 & 23.0 & 0.76 \\
\hline
\end{tabular}

$\mathrm{MoCa}=$ Montreal Cognitive Assessment, ${ }^{*}$ Mann-Whitney test; ${ }^{* *}$ seconds; EMG = episodic migraine group; $C G$ = control group . 
Table 6. Linear regression model, where the Montreal Cognitive Assessment test was the dependent variable, controlled by independent variables

\begin{tabular}{|c|c|c|c|c|c|}
\hline Independent variables & Coefficient B & Mean \pm SD & $p$-value & \multicolumn{2}{|c|}{$95 \%$ confidence interval for $\mathrm{E}$} \\
\hline Episodic migraine & -0.54 & 0.58 & 0.35 & -1.71 & 0.62 \\
\hline Use of topiramate & 1.74 & 1.77 & 0.33 & -1.80 & 5.29 \\
\hline Depressive disorder & -1.28 & 1.84 & 0.49 & -4.98 & 2.41 \\
\hline Anxiety disorder & 0.03 & 0.68 & 0.97 & -1.34 & 1.40 \\
\hline Non-restorative sleep & -1.11 & 0.66 & 0.87 & -1.42 & 1.21 \\
\hline
\end{tabular}

\section{DISCUSSION}

This paper described and analyzed the cognitive aspects in patients with a episodic migraine and non-migraine controls, matched by gender, age, and schooling, as well as evaluating the main trigger factors of cognitive disorders present, such as depressive disorder, anxiety disorder, use of topiramate, non-restorative sleep.

The topic of cognition and chronic pain has been studied more recently in some papers. Landrø et al. ${ }^{25}$ identified some possible reasons for these deficits, including the presence of depressive symptoms (which are present in 40 to $50 \%$ of patients with chronic pain) and drug use ${ }^{26}$. Another study, conducted by our research group, had already shown cognitive deficits in patients with chronic migraine compared to the $\mathrm{CG}^{20}$. A prospective study evaluated participants with migraine, with and without aura for cognitive function. Three cognitive tests were used: The Words List of the Consortium to Establish a Registry for Alzheimer Disease (CERAD), verbal fluency tests and Tracks. Patients with migraine without aura were associated with worse cognitive performance ${ }^{15}$.

The exact mechanism supporting the complex relationship between chronic pain and cognition has not been fully understood. There is a direct relation between attention, transient retention of information, immediate memory and the activity of neurons in the prefrontal cortex. What would be the physiological basis of this finding? First of all, the same neural networks that are used for many cognitive functions are also used for nociceptive functions. Secondly, bodily sensations can lead the individual to a state of hypervigilance and divert attention from other cognitive tasks. This hampers an effective response to new information. These results support the "neurocognitive model of the dynamics of attention to pain"6.

In this study, the EMG patients presented MoCa performance similar to the CG. There was also similar performance in the migraine group relative to the CG in the verbal fluency tests, Stroop test, and no significant statistic was found in the Mann-Whitney test.

These data are different from those found in a previous study that evaluated patients with chronic migraine and a CG, finding impairments in tasks that use attention (Stroop test), language (verbal fluency) and visuospatial abilities (clock design) ${ }^{20}$. The results also differ from other studies that have shown cognitive alterations in patients with migraine ${ }^{12-15}$ and resemble studies that did not find this alterations ${ }^{7-11}$. However, it is believed that an evaluation with a greater number of patients could be useful to explain these results better.
Although there is a small number of patients, it is possible to work with a paired sample by gender, schooling, and age. In addition, a linear regression model was used to control possible confounding variables. These variables, such as anxiety disorder, depressive disorder, drugs use, sleep disturbances, by influencing cognition, are major challenges for clinical studies that address the issue of chronic pain. In this study, it was possible to analyze these variables that would act as confounders in the $\mathrm{MoCa}$ test results through linear regression. Regarding the evaluation of episodic migraine, anxiety disorder, depressive disorder, use of topiramate and non-restorative sleep, none of these variables influenced the MoCa test. Thus, this study brings new information to the pertinent literature.

\section{CONCLUSION}

The results made us believe that patients with episodic migraine do not present cognitive deficits compared to a control group.

\section{REFERENCES}

1. Rasmussen BK. Epidemiology of headache. Cephalalgia. 2001;21(7):774-7.

2. Becker WJ, Gladstone JP, Aube M. Migraine prevalence, diagnosis, and disability. Can J Neurol Sci, 2007;34(4):3-9.

3. Speciali JG, Silva WF. Cefaléias. Săo Paulo: Lemos Editorial; 2002. 493p.

4. The International Classification of Headache Disorders: $3^{\text {rd }}$ ed. Cephalalgia. 2013;33(Suppl 9):644-58.

5. Giazomozzi AR, Vindas AP, Silva AA Jr, Bordini CA, Buonanotte CF, Roesler CA, et al. Latin American consensus on guidelines for chronic migraine treatment. Arq Neuropsiquiatr. 2013;71(7):478-86.

6. Berryman C, Stanton TR, Jane Bowering K, Tabor A, McFarlane A, Lorimer Moseley G. Evidence for working memory deficits in chronic pain: a systematic review and meta-analysis. Pain. 2013;154(8):1181-96.

7. McKendrick AM, Badcock DR, Badcock JC, Gurgone M. Motion perception in migraineurs: abnormalities are not related to attention. Cephalalgia. 2006;26(9):1131-6.

8. Leijdekkers ML, Passchier J, Goudswaard P, Menges LJ, Orlebeke JF. Migraine patients cognitively impaired? Headache. 1990;30(6):352-8

9. Gaist D, Pedersen L, Madsen C, Tsiropoulos I, Bak S, Sindrup S, et al. Long-term effects of migraine on cognitive function: a population-based study of Danish twins. Neurology. 2005;64(4):600-7

10. Jelicic M, van Boxtel MP, Houx PJ, Jolles J. Does migraine headache affect cognitive function in the elderly? Report from the Maastricht Aging Study (MAAS). Headache. 2000;40(9):715-9.

11. Pearson AJ, Chronicle EP, Maylor EA, Bruce LA. Cognitive function is not impaired in people with a long history of migraine: a blinded study. Cephalalgia. 2006;26(1):74-80.

12. Santos-Lasaosa S, Viloria-Alebesque A, Morandeira-Rivas C, Lopes Del Val LJ, Bellosta-Diago E, Velezquez-Benito A. Mnemonic complaints and chronic migraine. Rev Neurol. 2013;57(4):145-9. Spanish.

13. Hooker WD, Raskin NH. Neuropsychologic alterations in classic and common migraine. Arch Neurol. 1986;43(7):709-12.

14. Zeitlin C, Oddy M. Cognitive impairment in patients with severe migraine. Br J Clin Psychol. 1984;23(Pt 1):27-35.

15. Pellegrino Baena C, Goulart AC, Santos IS, Suemoto CK, Lotufo PA, Bensenor IJ Migraine and cognitive function: baseline findings from the Brazilian longitudinal 
study of adult health: ELSA-Brasil. Cephalalgia. 2017. 333102417737784. [Epub ahead of print].

16. Schwedt TJ, Dodick DW. Advanced neuroimagem of migraine. Lancet Neurol. 2009;8(6):560-8.

17. Lee S, Sziklas V, Andermann F, Farnham S, Risse G, Gustafson M, et al. The effects of adjunctive topiramate on cognitive function in patients with epilepsy. Epilepsia. 2003;44(3):339-47.

18. Yasuda CL, Centeno M, Vollmar C, Stretton J, Symms M, Cendes F, et al. The effect of topiramate on cognitive fMRI. Epilepsy Res. 2013;105(1-2):250-5.

19. Loring DW, Williamson DJ, Meador KJ, Wiegand F, Hilihan J. Topiramate dose effects on cognition: a randomized double-blind study. Neurology. 2011;76(2):131-7.

20. Ferreira KS, Teixeira CT, Cáfaro C, Oliver GZ, Carvalho GL, Carvalho LA, et al. Comprometimento cognitivo em pacientes com migrânea crônica é independente do uso de topiramato e comorbidades. Headache Med. 2017;3(8):89.

21. American Psychiatry Association. Diagnostic and statistical manual of mental disor- ders - DSM - 5. $5^{\text {th }}$ ed. Washington: American Psychiatric Association, 2013.

22. Memória CM, Yassuda MS, Nakano, EY, Forlenza OV. Brief screening for mild cognitive impairment: validation of Brazilian version of the Montreal cognitive assessment. Int J Geriatr Psychiatry. 2013;28(1):34-40.

23. Stroop JR. Studies interference in serial verbal reactions. J Exp Psychol. 1935;18:643-62.

24. SAS/ STAT User's Guide, Version 8, Cary, NC: SAS Institute Inc., 1999. R version 2.8.0 copyright $^{\odot} 2008$. the $\mathrm{r}$ foundation for statistical computing.

25. Landrø NI, Fors EA, Våpenstad LL, Holthe $\varnothing$, Stiles TC, Borchgrevink PC. The extent of neurocognitive dysfunction in a multidisciplinary pain centre population. Is there a relation between reported and tested neuropsychological functioning? Pain. 2013;154(7):972-7.

26. Silberstein SD, Hulihan J, Karim MR, Wu SC, Jordan D, Karvois D, et al. Efficacy and tolerability of topiramate $200 \mathrm{mg} / \mathrm{d}$ in the prevention of migraine with/without aura in adults: a randomized, placebo-controlled, double-blind, 12-week pilot study. Clin Ther. 2006;28(7):1002-11. 